\title{
TRANSPARÊNCIA E ACESSO À INFORMAÇÃO: QUEM É O CIDADÃO QUE DEMANDA A ABERTURA DE INFORMAÇÕES PÚBLICAS NO BRASIL? ${ }^{1}$
}

\author{
Alzira E. Angeli ${ }^{2}$
}

\begin{abstract}
RESUMO
Quem é o cidadão que demanda acesso à informação no Brasil? Que fatores podem explicar o uso do direito de acesso às informações públicas? Neste artigo, apresentam-se os resultados das análises realizadas sobre as características dos cidadãos que solicitaram acesso à informação aos órgãos e entidades do poder executivo federal a partir da vigência da Lei de Acesso à Informação até 31 de agosto de 2016. Os dados da pesquisa foram extraídos do "Sistema Eletrônico do Serviço de Informação ao Cidadão - e-SIC", disponíveis na Internet em formato aberto, o que possibilitou o exame da população de 203.521 usuários do sistema no período analisado. A estratégia metodológica consistiu na identificação da existência de diferenças significativas entre as distribuições de frequência dos cidadãos que demandaram informações do governo federal, considerando os atributos por eles indicados quando do preenchimento do cadastro individual no e-SIC: sexo, nível de escolaridade, profissão e local de residência. Os dados obtidos demonstraram o seguinte perfil do cidadão brasileiro "médio" que demanda acesso a informações públicas do governo federal: homem, 42 anos de idade, nível superior completo, profissão diferente das oferecidas no cadastro, residente na região sudeste do país.
\end{abstract}

Palavras-Chave: Governo Aberto, Transparência, Acesso à Informação, Abertura de Informações, Lei de Acesso à Informação.

\begin{abstract}
Who are the citizens demanding access to information in Brazil? Which are the factors that might explain the use of the "right to know"? This paper presents the results on the research about the individual characteristics of the Brazilian citizens who demand access to information from the federal government agencies upon the Freedom of Information Law requirements. The scope of analysis consists of all access to information requests up to August $31^{\text {st }}$ 2016. The research is based on the "Access to Information Service Electronic System - e-SIC" database, available on the Internet in open format, what has enabled the investigation on the whole population of 203,521 system's users. The methodological strategy consists of identifying the existence of significant differences between the frequency distributions of the citizens who demanded information from the federal government, considering the attributes indicated by themselves when completing the individual e-SIC register: sex, education level, profession and place of residence. The data obtained shows the profile of the "average" Brazilian citizen who demands access to public information from the federal government: male, 42 years of age, complete college level education, profession different from those offered in the registry, resident in the southeast region of the country.
\end{abstract}

Keywords: Open Government, Transparency, Access to Information, Openness of Information, Freedom of Information Law.

\section{RESUMEN}

¿Quién es el ciudadano que demanda acceso a la información en Brasil? ¿Qué factores podrían explicar el uso del derecho al acceso de las informaciones públicas? En este artículo se presentan los resultados de los análisis realizados sobre las características de los ciudadanos que solicitan acceso a la información de órganos y entidades del poder ejecutivo federal desde cuando entro en vigencia la "Ley de acceso a la información" hasta el 31 de agosto de 2016. Los datos utilizados en la investigación han sido extraídos del "Sistema electrónico del servicio de informaciones al ciudadano - e-SIC", de libre disponibilidad en internet, lo que posibilito el examen de una población de 203.531 usuarios del sistema, en ese periodo analizado. La estrategia metodológica consistió en identificar la existencia de diferencias significativas entre las distribuciones de frecuencia de los ciudadanos que demandaron informaciones al gobierno federal, considerando los atributos que ellos indicaron cuando llenaron el formulario individual de registro en el e-SIC: sexo, grado de escolaridad, profesión y local de residencia. Los datos obtenidos demostraron el siguiente perfil de ciudadano brasileño "medio" que demanda acceso a informaciones públicas del gobierno federal: hombre, 42 años de edad, grado superior completo, profesión diferente de las ofrecidas en el formulario de registro, residentes de la región sudeste del país.

\footnotetext{
${ }^{1}$ Enviado em: 07/09/2016.

Aceito para publicação em: 01/12/2016.

${ }^{2}$ Graduada em Comunicação Social e Mestranda em Ciência Política na Universidade Federal do Paraná. É pesquisadora em comunicação política, governo aberto e TICs.
} 
Palabras-clave: Gobierno Abierto, Transparencia, Acceso a la Información, datos de apertura, Acceso a la Información.

\section{INTRODUÇÃO}

Recentemente, a Lei de Acesso à Informação - LAI completou quatro anos de vigência no Brasil (Lei n ${ }^{\circ}$ 12.527, de 18 de novembro de 2011, vigente a partir de 16 de maio de 2012). Desde então, uma grande mudança na "cultura da informação" se impôs às instituições e aos servidores públicos brasileiros. Antes, regra; agora, o sigilo é exceção. Em substituição à tradicional confidencialidade das informações produzidas ou mantidas pela administração pública, como se privadas fossem, institui-se a abertura de informações a todo e qualquer cidadão, independentemente dos motivos determinantes da solicitação: “[...] franqueada, mediante procedimentos objetivos e ágeis, de forma transparente, clara e em linguagem de fácil compreensão" (BRASIL, 2011).

Segundo dados da UNESCO (2008), o Brasil foi uma das últimas democracias a regulamentar a abertura de informações públicas, embora o seu marco legal estivesse estabelecido desde a Constituição Federal de 1988, que, em seu artigo 5º, inciso XXXIII, garantiu ao cidadão o direito de acesso às informações públicas produzidas ou custodiadas pelo Estado brasileiro - the right to know - princípio fundamental de governo aberto.

No entanto, isso não foi impeditivo para o enorme avanço obtido na abertura de informações públicas ao longo dos pouco mais de quatro anos de vigência da LAI: 217.786 cidadãos apresentaram 412.154 pedidos de acesso à informação ao governo federal, segundo $\operatorname{dados}^{3}$ do Sistema Eletrônico do Serviço de Informação ao Cidadão - e-SIC, criado para operacionalizar a transparência passiva ${ }^{4}$ nos moldes da lei.

O portal de acesso à informação (http://www.acessoainformacao.gov.br/) apresenta algumas estatísticas gerais que apontam o uso crescente do direito de acesso à informação pelo cidadão brasileiro. Tem sido uma média mensal da ordem de oito mil pedidos no período analisado, dos quais se observa que apenas $1,56 \%$ não foram atendidos pelos órgãos públicos demandados.

Sob essa perspectiva, emergem as seguintes questões: quem é o cidadão que demanda acesso à informação no Brasil? O que explica o uso do direito de acesso a informações públicas?

A pesquisa tem por objeto o exame das características dos cidadãos que solicitaram acesso à informação aos órgãos e entidades do poder executivo federal desde o início da

\footnotetext{
3 Até 31 de Agosto de 2016.

4 “Transparência Passiva - a Administração Pública divulga informações sob demanda em atendimento às solicitações da sociedade" (CGU, 2011, p. 24).
} 
ANGELI, Alzira. Transparência e acesso à informação: quem é o cidadão que demanda a abertura de informações públicas no Brasil?

vigência da Lei de Acesso à Informação até agosto de 2016. Ao conhecer o perfil do cidadão "médio" que demanda acesso à informação, objetiva-se produzir dados que expliquem as relações entre esses atributos e o uso do direito de acesso a informações públicas no Brasil.

A estratégia metodológica consiste na análise das características da população de solicitantes de acesso à informação, por meio de estatística descritiva operada com o auxílio de software específico. Pretende-se identificar a existência ou não de diferenças significativas entre as distribuições de frequência dos cidadãos que demandam informações do governo federal, considerando os atributos por eles indicados quando do preenchimento do cadastro individual no e-SIC: sexo, nível de escolaridade, profissão e local de residência. Optou-se por utilizar essa metodologia, haja vista a intenção de dar tratamento estatístico às bases de dados do e-SIC, em sua totalidade, aproveitando a disponibilidade dessas informações no formato de "dados abertos". Entende-se que essa metodologia possibilitará identificar os atributos que possam explicar o uso do direito de acesso à informação pelos cidadãos brasileiros.

\section{DA PUBLICIDADE À TRANSPARÊNCIA}

Jürgen Habermas postula a publicidade como princípio de mediação entre política e moral. Contrapondo-se à prática do segredo de Estado, consideram-se injustas todas as ações que se referem ao direito de outros homens cujas máximas não se harmonizem com a publicidade: "Por isso é que a "publicidade" em Kant deve ser considerada como aquele princípio único a garantir o acordo da política com a moral. Ele [Kant] considera a "publicidade" como sendo, ao mesmo tempo, princípio da ordenação jurídica e método iluminista" (HABERMAS, 2003, p. 128).

Nesse sentido, Habermas (2003, p. 140) enfatiza que todas as máximas da ação política precisam da publicidade para coincidirem univocamente com o direito: "Num Estado de direito, uma política moral não quer dizer mais que um comportamento correto por obrigação decorrente de leis positivas. A soberania das leis é conseguida através da publicidade, ou seja, através de uma esfera pública cuja capacidade funcional é imposta sobretudo com a base natural do estado de direito". Em sintonia, no direito positivo brasileiro, é a publicidade, enquanto princípio constitucional que rege a administração pública, o pressuposto de eficácia das leis.

Precursor de Habermas na defesa da publicidade dos atos governamentais como princípio fundamental da política democrática, Jeremy Bentham (2011), ainda no século XIX, afirmou que a publicidade é "a lei mais adequada para se assegurar a confiança pública". Nesse mister, o filósofo inglês elencou as funções essenciais da publicidade enquanto 
impulsora do escrutínio público das decisões tomadas pelos governantes (Bentham, 2011): compelir os membros da assembleia a exercerem seu dever de ofício; - assegurar a confiança do povo e seu consentimento às medidas da legislatura; - possibilitar aos governantes conhecer os desejos dos governados; - possibilitar aos eleitores agirem a partir da compreensão dos temas em pauta; e - prover a assembleia com os recursos de benefícios obtidos a partir da informação do público.

Gutmann e Thompson $(1996 ; 2004)$ complementam a ideia de publicidade com uma acepção do termo voltada para delimitar o escopo da deliberação àqueles argumentos que sejam de natureza pública, ou seja, universalmente defensáveis. Nesse mister, dois autores brasileiros notam que:

Em relação ao princípio da publicidade, é válido destacar os preceitos kantianos da ética do discurso que são assim acionados por Habermas: o Princípio U, segundo o qual a deliberação depende de uma ética universalista, ou seja, os argumentos do debate devem ser universalmente válidos; o Princípio D, por outro lado, está ligado à defesa de Habermas de que o debate público permeie a vida cotidiana e abranja todos os concernidos (MARQUES e MIOLA, 2010, p. 5).

Como observou Marques em sua nota introdutória à tradução do texto de Bentham: “a ideia de publicidade tem se mostrado cada vez mais proeminente para abordagens vinculadas a diferentes perspectivas nas teorias democráticas, das liberais às de cunho deliberativo" (MARQUES, 2011, p. 277).

A partir da segunda metade do século passado, a transparência entrou na agenda dos teóricos da democracia e desde então tem sido, num número crescente de países, objeto de mecanismos para o seu fortalecimento, segundo Marques (2014). Nos passos do autor, convém salientar que o conceito de transparência não é consensual na literatura e também encara disputas terminológicas quando comparado a outras categorias - como a publicidade.

Ao discutir os conceitos de transparência, das concepções mais simples às definições mais complexas, Marques aponta que:

[...] a transparência se refere à condução aberta da administração da res publica, oferecendo aos cidadãos a capacidade de controlar o Estado e a atuação de seus agentes por meio do aprimoramento das estruturas de fiscalização, de denúncia e de punição daqueles que causarem prejuízos ao interesse coletivo (MARQUES, 2014, p. 6).

Para as pesquisadoras Sharon Dawes e Natalie Helbig (2010), a transparência pública possibilita o alcance de dois objetivos, ou de pelo menos um deles: o primeiro é oferecer uma “janela de observação" ao cidadão, através da qual se revelam os resultados das políticas governamentais e o próprio funcionamento da burocracia, constituindo-se em instrumento de 
ANGELI, Alzira. Transparência e acesso à informação: quem é o cidadão que demanda a abertura de informações públicas no Brasil?

accountability dos agentes e das instituições públicas; o segundo é abrir os bancos de dados governamentais, de forma a permitir que o cidadão faça uso das informações públicas para empreender ações que gerem valor econômico e social.

Segundo Marques (2014), existe uma concordância entre os estudiosos, mesmo que mínima, em torno da ideia de que a transparência é fundamental para a democracia, pois a clareza sobre o que se passa nos "bastidores" das decisões políticas permite ao cidadão comum exercer algum controle sobre a coisa pública.

\section{TRANSPARÊNCIA, ACESSO À INFORMAÇÃO E INTERNET}

A revisão da literatura revelou uma questão interessante: tem-se lançado um olhar conceitualmente simplista à abertura de informações públicas, haja vista que frequentemente correlaciona-se a disponibilização de informações com o seu uso e proveito de maneira automática.

A pesquisa realizada por Janssen, Charalabidis e Zuiderwijk (2012) identificou diversos benefícios potenciais advindos das iniciativas de transparência pública, os quais foram apresentados agrupados em três conjuntos: benefícios políticos e sociais; benefícios econômicos; e benefícios operacionais e tecnológicos. Os autores observaram que os resultados do grupo "benefícios políticos e sociais" foram percebidos pelos entrevistados como aqueles de maior importância, dentre os quais se destacam: - acesso aos dados por qualquer cidadão; - possibilidade de escrutínio dos dados; - participação e engajamento do cidadão; - melhoria dos processos de formulação de políticas públicas; - melhoria dos serviços públicos; - criação de serviços inovadores; - maior visibilidade aos provedores dos dados; - estímulo ao desenvolvimento do conhecimento; - descoberta de novas perspectivas no setor público. Quando perguntados pelas razões preponderantes para que sejam incentivadas as políticas de abertura de dados, os entrevistados apontaram a "ampliação da transparência" e a "melhoria dos mecanismos de accountability".

Por outro lado, os achados dessa mesma pesquisa demonstraram existir um abismo entre as vantagens prometidas pelos formuladores das políticas de abertura e divulgação de informações públicas e as barreiras enfrentadas para a sua adoção, descritas pelos próprios agentes responsáveis. Tal abismo manifestou-se a partir da descoberta de alguns "mitos" que emergiram das entrevistas realizadas, eis que, por um lado parecem argumentos sedutores a inspirar a ação coletiva; porém, de outro lado comportam-se de maneira a nublar a visão da realidade, já que não costumam necessariamente guardar compromisso com os fatos. Janssen, 
Charalabidis e Zuiderwijk (2012) concluíram que o entendimento desses mitos contribui para a compreensão das questões que circundam o tema, a saber:

“É simplesmente uma questão de disponibilizar as informações públicas”. Diferentemente do que se assume, a tarefa dos formuladores das políticas de abertura de dados não se restringe a apenas torná-los disponíveis. Se tais políticas são implementadas despidas de instrumentos que zelem pela qualidade e usabilidade das informações divulgadas, restam inúteis os esforços empreendidos diante das necessidades e expectativas dos usuários. É verdade que os governos (provedores dos dados) ainda não dispõem de instrumentos que demonstrem o que os cidadãos (usuários dos dados) têm feito com as informações acessadas e, nesse sentido, têm sido criticados pela pouca adoção dos princípios de accountability, ausência de mecanismos de avaliação e falta de feedback aos usuários, na visão de Dawes e Helbig (2010). Aliás, não há métrica apropriada para avaliar se a abertura de informações públicas é um sucesso. Segundo Bertot, McDermott e Smith (2012), as métricas existentes são todas ainda muito focadas na produção, por exemplo, quantos bancos de dados estão abertos ao público?

“Todo interessado é capaz de utilizar as informações divulgadas". O que se imagina é que qualquer cidadão possa diretamente fazer uso das informações públicas disponibilizadas, o que é verdadeiro em se tratando de consultas simples ou simplificadas mediante funcionalidades desenvolvidas para facilitar o manuseio das bases de dados pelos usuários comuns. No entanto, assumir que todos os usuários têm recursos e expertise para utilizar qualquer tipo de informação é uma generalização falsa, sobretudo se forem consideradas também as informações disponibilizadas sob o formato de dados abertos. Com efeito, essa afirmação desconsidera a perspectiva do usuário ao deixar de reconhecer que, a depender do que se pretenda fazer com as informações, são necessários requisitos técnicos para que se consiga acessá-las, reuni-las, processá-las, extrair-lhe sentido, conhecer suas implicações e relacionamentos, enfim ser capaz de empregar os dados com o proveito esperado.

"A abertura de informações automaticamente proporciona resultados positivos". Nos debates sobre a implantação de políticas de governo aberto, tem sido dominante a ideia que a divulgação de informações, por si só, permite ou até mesmo resulta nos benefícios esperados. Assim, evita-se admitir que existem barreiras que atrapalham ou mesmo impedem a utilização das informações públicas disponibilizadas e sugere-se que a mera abertura de dados é suficiente para que os usuários deles tirem proveito.

Nessa toada, Strathern (2000) já havia observado que governos abertos demandam transformações consideráveis nas estruturas de governança das organizações públicas e 
ANGELI, Alzira. Transparência e acesso à informação: quem é o cidadão que demanda a abertura de informações públicas no Brasil?

requerem bem mais do que permitir acesso às informações. Embora pressuposto para a transparência, a abertura de informações não é suficiente para o estabelecimento de um governo aberto e accountable. Às medidas para ampliação da transparência há que serem acrescentadas políticas e, sobretudo, instrumentos que estimulem o engajamento dos cidadãos na gestão governamental e que sejam capazes de propiciar o diálogo (permanente) entre governo e sociedade. Esses instrumentos, sem dúvida, envolvem o uso da Internet.

Norris (2001) contrapõe sua visão ao entendimento da maioria dos autores até então, sobretudo considerando a literatura existente nos Estados Unidos e na Europa Ocidental, com o argumento apropriado de que o papel fundamental da Internet é o fortalecimento das democracias, sobretudo daquelas em processo de consolidação, visto que a tecnologia contribui para a ampliação do acesso às informações públicas e dinamiza a comunicação dos cidadãos com as instituições políticas representativas. Com efeito, aos olhos de hoje, as análises da autora adquirem um tom profético.

Outrossim, na visão dos teóricos deliberacionistas: "Em última instância, não é possível negar que há um gigantesco aumento nas possibilidades de interações com outros indivíduos, que não precisam estar mais limitadas geográfica e temporalmente, o que tem grande potencial para as discussões políticas e deliberações informais, elementos valorizados nas teorias democráticas mais recentes" (HABERMAS, 1997; 2006, apud SAMPAIO).

\section{ACESSO À INFORMAÇÃO NO BRASIL}

A transparência, selo característico dos governos democráticos contemporâneos, relaciona-se diretamente com as leis de acesso à informação pública, a primeira delas promulgada em 1966 pelos Estados Unidos da América (Freedom of Information Act FOIA). A partir de então, outros países seguiram na criação de leis equivalentes: Dinamarca e Noruega em 1970; França e Holanda em 1978; Austrália, Canadá e Nova Zelândia em 1982; Hungria em 1992; Irlanda e Tailândia em 1997; Coréia do Sul em 1998; Reino Unido em 2000; Japão e México em 2002; Índia e Alemanha em 2005; e o Brasil em 2011.

No Brasil, o marco legal que permitiu a adoção de medidas para a transparência na gestão pública iniciou-se com a Constituição Federal de 1988, que garantiu ao cidadão o direito de acesso às informações públicas produzidas ou custodiadas pelo Estado brasileiro ao assegurar, em seu artigo $5^{\circ}$, inciso XXXIII, o princípio fundamental de governo aberto: "the right to know". Recentemente conferiu-se efetividade ao mandamento constitucional com a promulgação da Lei de Acesso à Informação (Lei $n^{\circ}$ 12.527, de 18 de novembro de 2011), regulamentada em nível federal pelo Decreto nº 7.724, de 16 de maio de 2012. 
Todavia, esse não foi o primeiro passo para a regulamentação específica do acesso à informação no Brasil. Esses esforços tiveram início com a Lei de Responsabilidade Fiscal (Lei Complementar $n^{\circ} 101$, de 4 de maio de 2000) que, ao estabelecer normas de finanças públicas voltadas para a responsabilidade na gestão fiscal, dedicou um capítulo à definição de instrumentos de transparência, ainda que apenas dirigidos àquele tema. Sob a vigência da Lei de Responsabilidade Fiscal, tornou-se obrigatória a divulgação, em meios eletrônicos de acesso público, dos planos, orçamentos e leis de diretrizes orçamentárias, bem como das prestações de contas e dos relatórios de execução orçamentária e de gestão fiscal.

Mais adiante, com os dispositivos acrescentados pela Lei Capiberibe (Lei Complementar $n^{\circ} 131$, de 27 de maio de 2009) cuidou-se de assegurar a transparência na gestão fiscal também mediante o incentivo à participação popular e a realização de audiências públicas durante o processo de elaboração e discussão do orçamento público. Ressalte-se que a medida inovadora introduzida pela Lei Capiberibe foi a obrigatoriedade de disponibilização, em tempo real, das informações pormenorizadas sobre a execução orçamentária e financeira dos entes da federação, o que provocou a criação dos "portais de transparência". Estados, municípios e o Distrito Federal espelharam-se no governo federal, que havia lançado o "Portal da Transparência" em 2004.

Nesse diapasão, foram criados diversos portais de informação ao cidadão, alguns deles também de prestação de serviços públicos, a exemplo do Portal de Compras do Governo Federal (http://www.comprasgovernamentais.gov.br/), do Portal de Convênios (https://www.convenios.gov.br/portal/) e do Portal Brasil (http://www.brasil.gov.br/). Essas iniciativas enquadram-se numa categoria que supera a mera disponibilização de informações públicas, como se observa: “[...] o governo aberto não precisa se restringir unicamente a uma mudança paradigmática da publicação de dados estatais, mas também pode ser fomentado através de diferentes projetos ou iniciativas de governo aberto, que busquem justamente fortalecer o poder da esfera civil nas tomadas de decisão" (SAMPAIO, 2014, p. 20).

Em razão desses avanços, quando iniciou a vigência da Lei de Acesso à Informação no país, alguma "cultura" de divulgação de dados já havia se desenvolvido nos órgãos públicos, sobretudo no âmbito federal, o que de certa forma favoreceu a adoção dos dispositivos de transparência ativa ${ }^{5}$ apenas 180 dias após a publicação da lei, enquanto em outros países o período de vacatio legis das normas equivalentes foi bem maior - dois anos no México e cinco anos no Reino Unido, por exemplo. Por sua vez, para operacionalizar a 
ANGELI, Alzira. Transparência e acesso à informação: quem é o cidadão que demanda a abertura de informações públicas no Brasil?

transparência passiva ${ }^{6}$ nos moldes da Lei de Acesso à Informação, foi criado o Sistema Eletrônico do Serviço de Informação ao Cidadão - e-SIC, disponível na Internet em http://www.acessoainformacao.gov.br/sistema/site/index.html desde o primeiro dia de vigência da lei.

\section{METODOLOGIA E ANÁLISES}

Todo pedido de acesso à informação destinado aos órgãos e entidades do poder executivo federal brasileiro é realizado diretamente no Sistema Eletrônico do Serviço de Informação ao Cidadão - e-SIC, em plataforma web, ou nele são registrados, por servidor público, os dados preenchidos pelo cidadão em formulário em papel, nos casos em que a demanda é apresentada pessoalmente no Serviço de Informação ao Cidadão - SIC de cada repartição. Dessa forma, pode-se afirmar que o e-SIC é o instrumento único e universal para o recebimento e atendimento dos pedidos de acesso à informação naquele âmbito.

Para proceder ao pedido de informação, no primeiro acesso ao e-SIC o cidadão preenche um cadastro, cujos campos obrigatórios são "nome completo", "documento de identificação" e "e-mail". Os demais campos, de preenchimento facultativo, são: "data de nascimento", “sexo", “escolaridade", “profissão", “endereço", “país”, “UF”, “cidade”, “CEP”, "telefone".

A seguir, apresentam-se para ilustração as telas iniciais para o preenchimento do cadastro individual do solicitante de acesso à informação no e-SIC:

Figura $\mathbf{n}^{\mathbf{0}} \mathbf{1}$ - Tela para o primeiro acesso ao e-SIC:

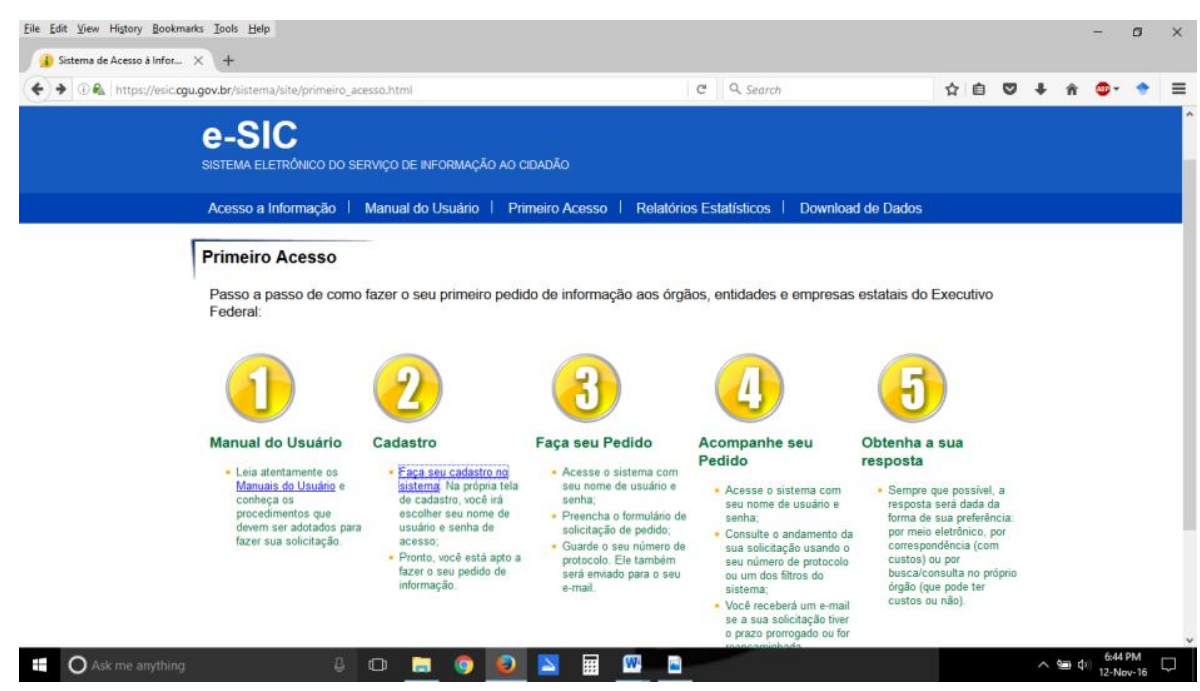

6 "Transparência Passiva - a Administração Pública divulga informações sob demanda em atendimento às solicitações da sociedade" (CGU, 2011, p. 24). 
Figura $\mathbf{n}^{\mathbf{0}} \mathbf{2}$ - Tela para o cadastro do solicitante de acesso à informação no e-SIC:

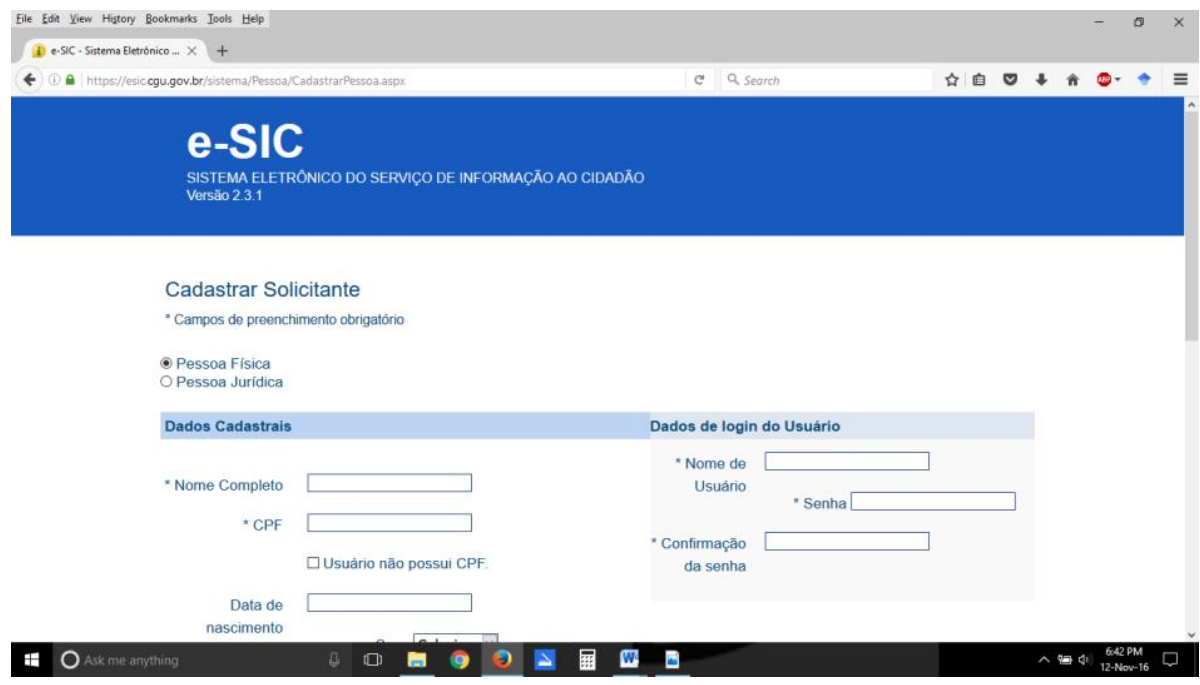

Figura n⿳0 3 - Tela para o cadastro do solicitante de acesso à informação no e-SIC - detalhe:

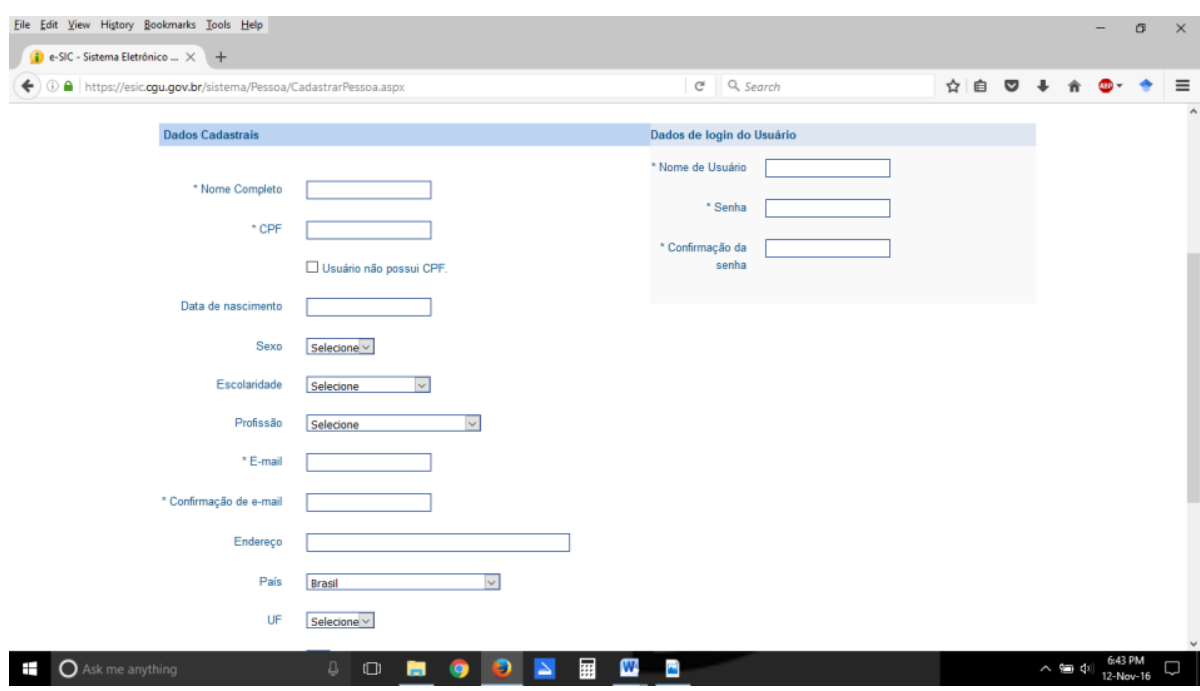

Esse conjunto de registros do e-SIC, relativamente ao período de 16 de maio de 2012 (o primeiro dia de vigência da lei) a 31 de agosto de 2016, disponível em formato aberto, ${ }^{7}$ constituiu a fonte de dados para a realização da pesquisa.

A pesquisa tem por objeto o exame das características dos cidadãos que solicitaram acesso à informação aos órgãos e entidades do poder executivo federal desde o início da vigência da Lei de Acesso à Informação até agosto de 2016 e foi conduzida com o objetivo de obter dados empíricos que expliquem as relações entre esses atributos e o uso do direito de acesso à informação no Brasil.

${ }^{7}$ http://www.acessoainformacao.gov.br/sistema/Relatorios/Anual/DownloadDados.aspx 
ANGELI, Alzira. Transparência e acesso à informação: quem é o cidadão que demanda a abertura de informações públicas no Brasil?

A partir das características informadas pelos próprios solicitantes ("data de nascimento", "sexo", “escolaridade", "profissão" e "local de residência"), consideradas as possíveis categorias de cada uma dessas variáveis independentes, examinou-se a população de usuários do e-SIC, de forma a identificar a existência ou não de diferenças significativas entre as distribuições de frequência dos cidadãos que demandam informações do governo federal.

As análises foram realizadas por meio de estatística descritiva operada com o auxílio de software específico. A estratégia metodológica adotada permitiu dar tratamento estatístico às bases de dados do e-SIC, em sua totalidade, aproveitando a disponibilidade dessas informações no formato de "dados abertos".

Convém observar que nada impede que o cidadão declare informações inverídicas quando do preenchimento do cadastro no e-SIC, o que, mesmo em pequena medida, pode prejudicar a confiabilidade das conclusões desta pesquisa.

Desse modo, tendo em vista os objetivos propostos, buscou-se confirmar as seguintes hipóteses:

- os cidadãos brasileiros têm, independentemente de sexo, a mesma disposição para fazer uso do direito de acesso à informação;

- o uso do direito de acesso à informação é mais frequente entre os cidadãos com nível de escolaridade mais alto;

- cidadãos que atuam em certas profissões como jornalistas, ou pesquisadores, têm mais disposição de fazer uso do direito de acesso à informação;

- As regiões sul e sudeste são aquelas que concentram mais pedidos de acesso à informação.

Considerações sobre a população objeto de exame:

De 16 de maio de 2012 até 31 de agosto de 2016, o governo federal recebeu o total de 411.432 pedidos de acesso à informação, demandados por 234.571 solicitantes, como mostrado no quadro $\mathrm{n}^{\mathrm{o}} 1$, a seguir:

Quadro n' 1 - evolução dos pedidos de acesso à informação no Brasil.

\begin{tabular}{|r|c|r|}
\hline \multicolumn{1}{|c|}{ Ano } & $\begin{array}{c}\text { Quantidade de pedidos de } \\
\text { acesso à informação }\end{array}$ & $\begin{array}{c}\text { Quantidade de demandantes } \\
\text { de acesso à informação }\end{array}$ \\
\hline$* 2012$ & 55.212 & 35.568 \\
\hline 2013 & 86.661 & 51.638 \\
\hline 2014 & 90.167 & 51.207 \\
\hline
\end{tabular}




\begin{tabular}{|r|r|r|}
\hline 2015 & 102.423 & 55.302 \\
\hline$* * 2016$ & 77.691 & 40.856 \\
\hline Total & 412.154 & $* * * 234.571$ \\
\hline
\end{tabular}

Fonte: dados do e-SIC

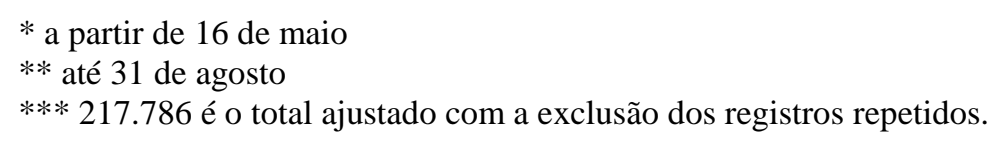

É necessário esclarecer que a somatória dos valores apresentados na coluna anterior "quantidade de demandantes de acesso à informação" computa indevidamente 16.785 registros repetidos. Isso porque os registros dos solicitantes de acesso à informação disponibilizados pelo e-SIC ${ }^{8}$ estão apresentados em banco de dados individualizado pelo ano em que os pedidos foram realizados. Dessa maneira, ao se juntar os bancos de dados dos solicitantes em 2012, 2013, 2014, 2015 e 2016, o registro de um mesmo indivíduo aparece computado tantas vezes quantas ele requereu acesso à informação, exceto se o fez mais de uma vez dentro do mesmo exercício.

Pode-se exemplificar essa circunstância quando se considera o caso do demandante sob "IdSolicitante" número 12. Constatou-se que esse cidadão requereu informações em 2014, 2015 e 2016, razão pela qual seu registro foi computado três vezes no total dos solicitantes de 2012 a 2016. Outrossim, verificou-se similar ocorrência com os demandantes identificados sob o número 29 e o número 138. Esses cidadãos solicitaram acesso à informação em 2012 e em 2013. Por isso, seus registros estão duplicados no banco de dados dos solicitantes de 2012 a 2016. Procedeu-se, então, à exclusão dos 16.785 registros repetidos e se obteve o quantitativo de 217.786 demandantes de acesso à informação no período de 16 de maio de 2012 a 31 de Agosto de 2016.

Desse total de 217.786 solicitantes de acesso à informação, 10.742 identificaram-se, no cadastro, como pessoa jurídica, o equivalente a 4,93\% do total. Optou-se por excluir esses registros da base de dados objeto de análise, tendo em vista que os objetivos desta pesquisa têm por escopo a análise das características do cidadão. Restaram, então, os registros de 207.044 pessoas físicas.

Do mesmo modo, em razão dos objetivos propostos, decidiu-se pela exclusão dos registros dos cidadãos que não apresentaram nenhuma identificação quando do preenchimento do cadastro no e-SIC: nem idade, nem sexo, nem escolaridade, nem profissão, nem local onde residem. Então, foram excluídos 3.523 registros $(1,70 \%)$, restando 203.521 na base de dados.

\footnotetext{
${ }^{8}$ Formato de dados abertos em http://esic.cgu.gov.br/sistema/Relatorios/Anual/DownloadDados.aspx

9 Identificador único do solicitante atribuído mediante cadastro do CPF/CNPJ
} 
ANGELI, Alzira. Transparência e acesso à informação: quem é o cidadão que demanda a abertura de informações públicas no Brasil?

Portanto, a população objeto das análises constituiu-se dos registros de 203.521 solicitantes de acesso à informação que se identificaram como pessoas físicas e que apresentaram alguma característica quando do preenchimento do primeiro cadastro no e-SIC.

Resultados das análises:

Da análise dos atributos desses 203.521 cidadãos, foram obtidos os seguintes resultados:

a) Sobre o Sexo: 8.991 solicitantes de acesso à informação $(4,42 \%)$ não informaram o sexo. Dos 194.530 cidadãos que informaram o sexo, 113.244 são homens e 81.286 são mulheres.

Quadro no 2 - distribuição de frequência por sexo

\begin{tabular}{|l|r|r|}
\hline Homens & 113.244 & $58,21 \%$ \\
\hline Mulheres & 81.286 & $41,79 \%$ \\
\hline Total & 194.530 & $100,00 \%$ \\
\hline
\end{tabular}

Fonte: dados do e-SIC

b) Sobre a Escolaridade: 18.289 solicitantes de acesso à informação $(8,99 \%)$ não informaram a escolaridade. Dos 185.232 que informaram, obteve-se a seguinte distribuição de frequência de solicitantes de acesso à informação por nível de instrução:

Quadro no 3 - distribuição de frequência por escolaridade

\begin{tabular}{|l|r|r|}
\hline Ensino Superior & 75.050 & $40,52 \%$ \\
\hline Ensino Médio & 50.513 & $27,27 \%$ \\
\hline Pós-graduação & 33.064 & $17,85 \%$ \\
\hline Mestrado/Doutorado & 15.661 & $8,45 \%$ \\
\hline Ensino Fundamental & 9.364 & $5,06 \%$ \\
\hline Sem instrução formal & 1.580 & $0,85 \%$ \\
\hline Total & 185.232 & $100,00 \%$ \\
\hline
\end{tabular}

Fonte: dados do e-SIC 
c) Sobre a Profissão: 28.788 solicitantes de acesso à informação $(14,14 \%)$ não informaram a profissão. Dos 174.733 que informaram, obteve-se a seguinte distribuição de frequência de solicitantes de acesso à informação por profissão:

Quadro no 4 - distribuição de frequência por profissão

\begin{tabular}{|l|r|r|}
\hline Outra & 38.518 & $22,04 \%$ \\
\hline Empregado - setor privado & 32.041 & $18,34 \%$ \\
\hline Estudante & 20.939 & $11,98 \%$ \\
\hline Servidor público federal & 19.178 & $10,98 \%$ \\
\hline Profissional liberal/autônomo & 14.622 & $8,37 \%$ \\
\hline Servidor público estadual & 10.992 & $6,29 \%$ \\
\hline Professor & 10.876 & $6,22 \%$ \\
\hline Empresário/empreendedor & 10.356 & $5,93 \%$ \\
\hline Servidor público municipal & 9.590 & $5,49 \%$ \\
\hline Pesquisador & 3.902 & $2,23 \%$ \\
\hline Jornalista & 2.513 & $1,44 \%$ \\
\hline Membro de ONG nacional & 652 & $0,37 \%$ \\
\hline Representante de sindicato & 254 & $0,15 \%$ \\
\hline Membro de partido político & 201 & $0,12 \%$ \\
\hline Membro de ONG internacional & 99 & $0,06 \%$ \\
\hline Total & 174.733 & $100,00 \%$ \\
\hline
\end{tabular}

Fonte: dados do e-SIC

Convém aqui observar que, dada a maneira como as profissões são apresentadas para escolha quando do preenchimento do cadastro do e-SIC, é provável que haja alguma imprecisão quanto às informações registradas nesse campo. Isso porque a lista de profissões não contém itens mutuamente excludentes. Por exemplo, um professor, ou um pesquisador, ou um jornalista podem ser tanto empregados do setor privado, como servidores públicos, ou até mesmo profissionais liberais/autônomos. Sob esse raciocício, pode-se justificar que o percentual de cidadãos que registraram a sua profissão como "outra" (aliás, a "profíssão" mais escolhida) decorre da ambiguidade das opções apresentadas para registro da profissão.

d) Sobre o local de residência: 1.239 solicitantes de acesso à informação $(0,61 \%)$ informaram residir fora do Brasil. Dos 202.282 solicitantes de acesso à informação que informaram residir no Brasil, 6.182 (3,06\%) não informaram a unidade da federação onde residem. Dos 196.100 que informaram a unidade da federação onde residem, obteve-se a seguinte distribuição de frequência de solicitantes de acesso à informação por região: 
ANGELI, Alzira. Transparência e acesso à informação: quem é o cidadão que demanda a abertura de informações públicas no Brasil?

Quadro n' 5 - distribuição de frequência por região

\begin{tabular}{|l|r|r|}
\hline Sudeste & 97.788 & $49,87 \%$ \\
\hline Nordeste & 33.653 & $17,16 \%$ \\
\hline Sul & 27.608 & $14,08 \%$ \\
\hline Centro-Oeste & 26.270 & $13,40 \%$ \\
\hline Norte & 10.781 & $5,50 \%$ \\
\hline Total & 196.100 & $100,00 \%$ \\
\hline
\end{tabular}

Por seu turno, 8.982 solicitantes de acesso à informação $(4,41 \%)$ também não informaram o município onde residem. Obteve-se então a distribuição de frequência dos 194.539 solicitantes que informaram o município onde residem, cujo resultado para três cidades (Brasília, Rio de Janeiro e São Paulo) merece destaque:

Quadro no 6 - distribuição de frequência - Brasília, Rio de Janeiro, São Paulo

\begin{tabular}{|l|r|r|r|r|}
\hline & $\begin{array}{c}\text { Solicitantes de } \\
\text { Acesso à } \\
\text { Informação }\end{array}$ & $\begin{array}{c}\text { Proporção de } \\
\text { Solicitantes em } \\
\text { relação ao total de } \\
\text { Solicitantes }\end{array}$ & $\begin{array}{c}\text { População } \\
\text { Estimada em } \\
2016^{10}\end{array}$ & $\begin{array}{c}\text { Proporção de } \\
\text { Solicitantes em } \\
\text { relação à } \\
\text { População }\end{array}$ \\
\hline Brasília & 15.261 & $7,845 \%$ & 2.977 .216 & $0,513 \%$ \\
\hline Rio de Janeiro & 15.254 & $7,841 \%$ & 6.498 .837 & $0,235 \%$ \\
\hline São Paulo & 19.605 & $10,078 \%$ & 12.038 .175 & $0,163 \%$ \\
\hline Demais cidades & 144.419 & $74,237 \%$ & 184.967 .772 & $0,078 \%$ \\
\hline Todo o país & 194.539 & $100 \%$ & 206.482 .000 & $0,094 \%$ \\
\hline
\end{tabular}

Gráfico no 1 - Proporção de solicitantes de acesso à informação residentes em Brasília, Rio de Janeiro e São Paulo comparativamente com os residentes nas outras cidades do país:



${ }^{10}$ Segundo dados do IBGE. 
É interessante observar que apenas três cidades concentram um quarto de todos os solicitantes de acesso à informação (25,76\%): Brasília, Rio de Janeiro e São Paulo. E que Rio de Janeiro e Brasília apresentaram basicamente a mesma frequência de solicitantes, embora Brasília tenha menos da metade da população do município do Rio de Janeiro. Aliás, pode-se dizer que Brasília possui quatro vezes mais solicitantes de acesso à informação do que os demais municípios brasileiros.

e) Sobre a Idade: 18.311 solicitantes de acesso à informação (9\%) não informaram a data de nascimento. Dos 185.210 que informaram a data de nascimento, obteve-se a distribuição de frequência de solicitantes de acesso à informação por faixa etária. Observe-se que a média de idade da população foi calculada em 41,9 anos e a mediana das idades é de 39 anos.

Quadro 7 - distribuição de frequência por faixa etária

\begin{tabular}{|l|r|r|}
\hline até 14 anos & 243 & $0,13 \%$ \\
\hline de 15 a 18 anos & 988 & $0,53 \%$ \\
\hline de 19 a 24 anos & 14.261 & $7,70 \%$ \\
\hline de 25 a 34 anos & 52.369 & $28,28 \%$ \\
\hline de 35 a 44 anos & 44.631 & $24,10 \%$ \\
\hline de 45 a 54 anos & 34.759 & $18,77 \%$ \\
\hline de 55 a 64 anos & 25.105 & $13,55 \%$ \\
\hline de 65 a 74 anos & 9.517 & $5,14 \%$ \\
\hline mais de 75 anos & 3.337 & $1,80 \%$ \\
\hline Total & 185.210 & $100,00 \%$ \\
\hline
\end{tabular}

Por sua vez, considerando-se os 164.328 solicitantes de acesso à informação que se identificaram completamente, preenchendo todos os campos do formulário quando do cadastro no e-SIC, pode-se traçar o perfil do cidadão brasileiro "médio" que demanda acesso a informações públicas do governo federal: homem, 42 anos de idade, nível superior completo, profissão diferente das oferecidas no cadastro, residente na região sudeste do país.

Posto isso, passa-se a verificar os atributos mais específicos desses cidadãos, de modo a descobrir se há características concentradas em determinados perfis, especialmente considerando o sexo, uma vez que há mais pedidos de acesso solicitados por homens, e a região de onde se originaram os pedidos de acesso, dado o destaque da região sudeste, como mostrou o perfil do cidadão médio que se dispõe a requerer acesso à informação. 
ANGELI, Alzira. Transparência e acesso à informação: quem é o cidadão que demanda a abertura de informações públicas no Brasil?

Para tratar essa questão, aplicou-se o teste do resíduo padronizado ${ }^{11}$, com o intuito de verificar a concentração ou desconcentração dos atributos em determinada categoria das variáveis independentes analisadas. Em complemento, realizou-se o teste $V$ de Cramer, que mede a força da associação entre as variáveis. Os testes realizados mostraram dependências estatisticamente significativas ( $\operatorname{sig}=0,000$ ) nas seguintes relações concernentes aos cidadãos que solicitaram acesso à informação no período estudado: sexo e escolaridade; sexo e profissão na região sudeste; local de residência e faixa etária. As tabelas $n^{\circ} 1, n^{\circ} 2$ e $n^{\circ} 3$ a seguir apresentam o resíduo padronizado para as relações examinadas.

Tabela $\mathbf{n}^{\circ}$ 1: Escolaridade x Sexo

\begin{tabular}{|c|c|c|c|c|c|}
\hline & & & \multicolumn{2}{|c|}{ Sexo } & \multirow[t]{2}{*}{ Total } \\
\hline & & & Masculino & Feminino & \\
\hline \multirow{18}{*}{ Escolaridade } & \multirow{3}{*}{ Sem instrução formal } & Contagem & 770 & 791 & 1,561 \\
\hline & & $\%$ Sexo & $0.7 \%$ & $1.0 \%$ & $0.8 \%$ \\
\hline & & Resíduo Padrão & -4.6 & 5.5 & \\
\hline & \multirow{3}{*}{ Ensino Fundamental } & Contagem & 5,473 & 3,824 & 9,297 \\
\hline & & $\%$ Sexo & $5.1 \%$ & $5.0 \%$ & $5.1 \%$ \\
\hline & & Resíduo Padrão & .7 & -.9 & \\
\hline & \multirow{3}{*}{ Ensino Médio } & Contagem & 30,631 & 19,485 & 50,116 \\
\hline & & $\%$ Sexo & $28.6 \%$ & $25.4 \%$ & $27.3 \%$ \\
\hline & & Resíduo Padrão & 8.3 & -9.8 & \\
\hline & \multirow{3}{*}{ Ensino Superior } & Contagem & 43,851 & 30,633 & 74,484 \\
\hline & & $\%$ Sexo & $40.9 \%$ & $40.0 \%$ & $40.5 \%$ \\
\hline & & Resíduo Padrão & 2.1 & -2.5 & \\
\hline & \multirow{3}{*}{ Pós-graduação } & Contagem & 17,578 & 15,242 & 32,820 \\
\hline & & $\%$ Sexo & $16.4 \%$ & $19.9 \%$ & $17.9 \%$ \\
\hline & & Resíduo Padrão & -11.2 & 13.3 & \\
\hline & \multirow{3}{*}{ Mestrado/Doutorado } & Contagem & 8,820 & 6,700 & 15,520 \\
\hline & & $\%$ Sexo & $8.2 \%$ & $8.7 \%$ & $8.4 \%$ \\
\hline & & Resíduo Padrão & -2.4 & 2.8 & \\
\hline \multirow{2}{*}{ Total } & & Contagem & 107,123 & 76,675 & 183,798 \\
\hline & & $\%$ Sexo & $100.0 \%$ & $100.0 \%$ & $100.0 \%$ \\
\hline
\end{tabular}

O V de Cramer para a relação entre escolaridade e sexo é de 0,054 , calculado a partir do Qui-Quadrado de Pearson de 544, o que significa que o nível de instrução dos solicitantes explica apenas $5,44 \%$ do uso do direito de acesso à informação diferenciado por homens ou por mulheres. A tabela $n^{\circ} 1$ indica, a partir dos resíduos significativos, por exemplo, que homens com Ensino Médio e Superior tendem a utilizar mais o acesso à informação do que

\footnotetext{
${ }^{11}$ Considerando o intervalo de confiança adotado para o teste $(95 \%, z=1,96)$, qualquer resíduo acima de $+1,96$ ou abaixo de -1,96 é estatisticamente significativo. O resíduo positivo indica que a incidência do fenômeno observado apresenta-se acima do esperado, tendo em vista a hipótese nula de que a distribuição de frequência entre as categorias das variáveis seja aleatória. Inversamente, o resíduo negativo indica que a incidência do fenômeno observado está abaixo do que dele se espera, também diante da situação hipotética de que a distribuição de frequência entre as categorias das variáveis seja aleatória (CERVI, 2014).
} 
mulheres com o mesmo nível de escolaridade. Por outro lado, entre aqueles que têm pósgraduação, há uma concentração de mulheres que solicitam mais acesso à informação.

Tabela no 2: Região Sudeste - Profissão x Sexo

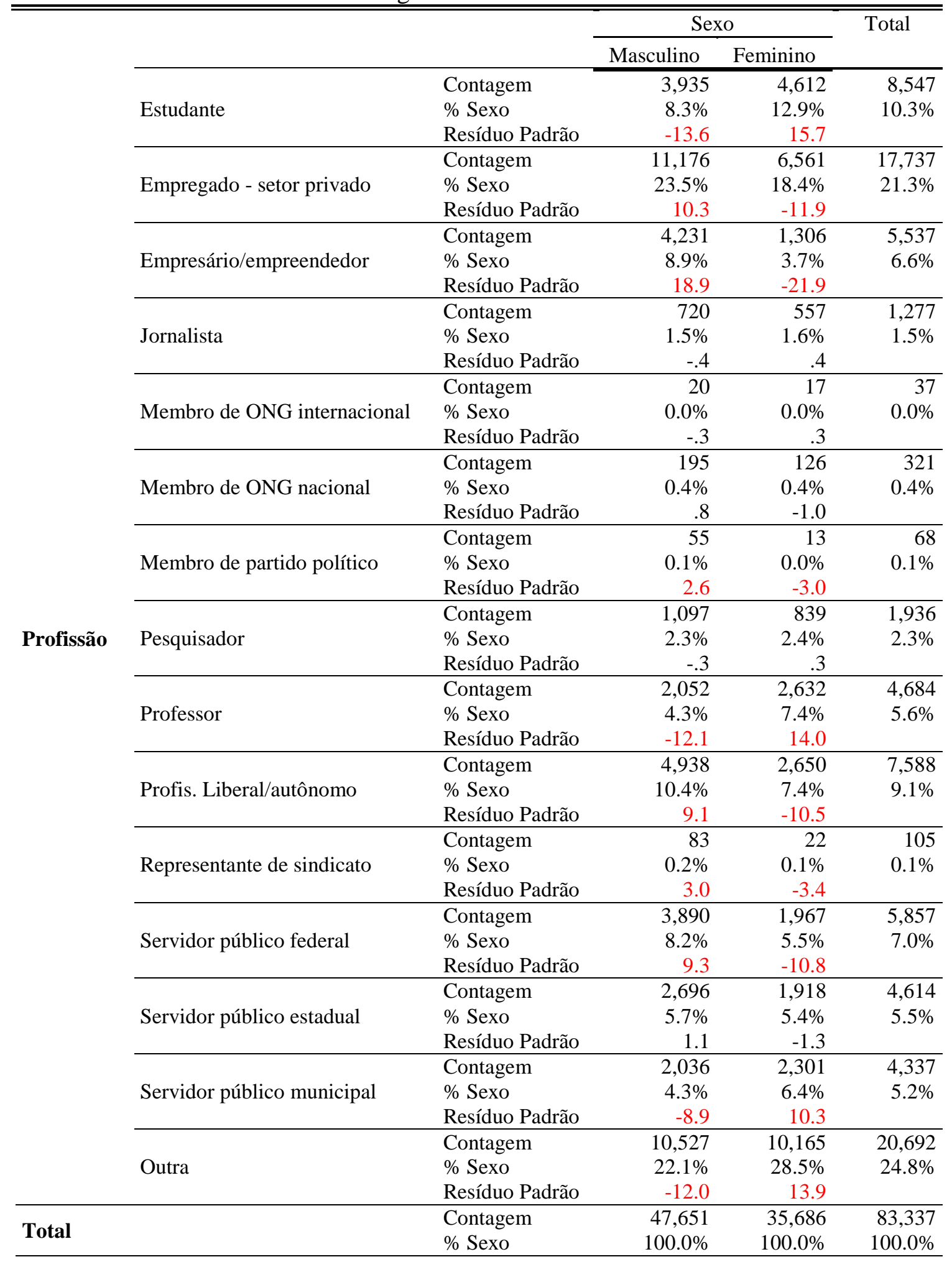


ANGELI, Alzira. Transparência e acesso à informação: quem é o cidadão que demanda a abertura de informações públicas no Brasil?

Se for considerada apenas a região sudeste, eis que agrega a metade dos solicitantes de acesso à informação $(49,87 \%)$, tem-se que o $V$ de Cramer para a relação entre profissão e sexo é de 0,184 (Qui-Quadrado de Pearson = 2.818), o que indica que a ocupação profissional dos solicitantes explica $18,40 \%$ do uso do direito de acesso à informação diferenciada por sexo. Considerando os resíduos padronizados significativos e positivos, temse que os homens concentram as profissões de empregado do setor privado, empresário e servidor público federal. Já para o sexo feminino, a concentração significativa se dá nas profissões professor, estudante e servidor público municipal.

Tabela no 3: Faixa Etária x Região

\begin{tabular}{|c|c|c|c|c|c|c|c|}
\hline & & \multicolumn{5}{|c|}{ Região } & \multirow[t]{2}{*}{ Total } \\
\hline & & Norte & Nordeste & Sudeste & Sul & C-Oeste & \\
\hline \multirow{3}{*}{ até 14 anos } & Contagem & 12 & 46 & 113 & 32 & 32 & 235 \\
\hline & \% Região & $0.1 \%$ & $0.1 \%$ & $0.1 \%$ & $0.1 \%$ & $0.1 \%$ & $0.1 \%$ \\
\hline & Resíduo Padrão & -.3 & .8 & -.3 & .0 & -.1 & \\
\hline \multirow{3}{*}{ de 15 a 18 anos } & Contagem & 54 & 233 & 430 & 119 & 119 & 955 \\
\hline & \% Região & $0.5 \%$ & $0.7 \%$ & $0.5 \%$ & $0.5 \%$ & $0.5 \%$ & $0.5 \%$ \\
\hline & Resíduo Padrão & .1 & 5.2 & -1.9 & -1.0 & -1.2 & \\
\hline \multirow{3}{*}{ de 19 a 24 anos } & Contagem & 821 & 2,720 & 6,060 & 1,947 & 2,081 & 13,629 \\
\hline & \% Região & $8.2 \%$ & $8.7 \%$ & $6.8 \%$ & $7.9 \%$ & $8.3 \%$ & $7.6 \%$ \\
\hline & Resíduo Padrão & 2.1 & 7.1 & -8.3 & 1.9 & 4.5 & \\
\hline \multirow{3}{*}{ de 25 a 34 anos } & Contagem & 3,055 & 10,042 & 21,864 & 6,866 & 8,188 & 50,015 \\
\hline & \% Região & $30.3 \%$ & $32.0 \%$ & $24.5 \%$ & $27.8 \%$ & $32.8 \%$ & $27.8 \%$ \\
\hline & Resíduo Padrão & 4.9 & 14.3 & -18.3 & .2 & 15.2 & \\
\hline \multirow{3}{*}{35 a 44 anos } & Contagem & 2,729 & 7,563 & 20,562 & 6,093 & 6,456 & 43,403 \\
\hline & \% Região & $27.1 \%$ & $24.1 \%$ & $23.1 \%$ & $24.7 \%$ & $25.9 \%$ & $24.1 \%$ \\
\hline & Resíduo Padrão & 6.2 & .1 & -6.2 & 1.9 & 5.7 & \\
\hline \multirow{3}{*}{ de 45 a 54 anos } & Contagem & 1,813 & 5,310 & 18,126 & 4,855 & 4,206 & 34,310 \\
\hline & \% Região & $18.0 \%$ & $16.9 \%$ & $20.3 \%$ & $19.7 \%$ & $16.9 \%$ & $19.0 \%$ \\
\hline & Resíduo Padrão & -2.4 & -8.6 & 8.9 & 2.3 & -7.9 & \\
\hline \multirow{3}{*}{ de 55 a 64 anos } & Contagem & 1,143 & 3,529 & 14,279 & 3,294 & 2,622 & 24,867 \\
\hline & \% Região & $11.4 \%$ & $11.3 \%$ & $16.0 \%$ & $13.4 \%$ & $10.5 \%$ & $13.8 \%$ \\
\hline & Resíduo Padrão & -6.6 & -12.2 & 17.9 & -1.9 & -14.0 & \\
\hline \multirow{3}{*}{ de 65 a 74 anos } & Contagem & 331 & 1,373 & 5,650 & 1,138 & 947 & 9,439 \\
\hline & \% Região & $3.3 \%$ & $4.4 \%$ & $6.3 \%$ & $4.6 \%$ & $3.8 \%$ & $5.2 \%$ \\
\hline & Resíduo Padrão & -8.6 & -6.7 & 14.4 & -4.3 & -10.0 & \\
\hline \multirow{3}{*}{ mais de 75 anos } & Contagem & 111 & 546 & 2,021 & 328 & 298 & 3,304 \\
\hline & \% Região & $1.1 \%$ & $1.7 \%$ & $2.3 \%$ & $1.3 \%$ & $1.2 \%$ & $1.8 \%$ \\
\hline & Resíduo Padrão & -5.4 & -1.2 & 9.6 & -5.9 & -7.5 & \\
\hline \multirow{2}{*}{ Total } & Contagem & 10,069 & 31,362 & 89,105 & 24,672 & 24,949 & 180,157 \\
\hline & \% Região & $100.0 \%$ & $100.0 \%$ & $100.0 \%$ & $100.0 \%$ & $100.0 \%$ & $100.0 \%$ \\
\hline
\end{tabular}

Com relação à faixa etária dos requerentes de acesso à informação, optou-se por cotejá-la com a variável região geográfica de residência. O V de Cramer obtido para essa relação é de 0,122, calculado a partir do Qui-Quadrado de Pearson de 2.676, o que demonstra 
que a idade dos solicitantes explica $12,19 \%$ do uso do direito de acesso à informação por região. Destaca-se, a partir dos resíduos padronizados, que a região sudeste tende, em comparação com as demais regiões do país, a concentrar os cidadãos mais velhos, acima dos 45 anos de idade.

\section{CONSIDERAÇÕES FINAIS}

Este trabalho teve por objetivo descobrir o perfil do cidadão "médio" que demanda a abertura de informações públicas no Brasil, com a pretensão de apontar os atributos que explicam a maior disposição de fazer uso do direito de acesso à informação.

A partir da análise das características informadas pelos solicitantes de acesso à informação no cadastro do Sistema Eletrônico do Serviço de Informação ao Cidadão - e-SIC, tomadas desde o início da vigência da Lei de Acesso à Informação até 31 de agosto de 2016, confirmaram-se algumas das hipóteses de trabalho, ao passo em que outras restaram afastadas, a saber:

- a grosso modo, os homens estão mais dispostos a solicitar acesso à informação, pois $58 \%$ dos demandantes são do "sexo masculino". Esse achado por certo refutou a hipótese de que, independentemente de sexo, os cidadãos brasileiros teriam a mesma disposição para fazer uso do direito de acesso à informação;

- cerca de $67 \%$ dos solicitantes de acesso à informação têm "nível superior" $(40,52 \%)$ ou "pós-graduação" $(17,85 \%)$ ou "mestrado/doutorado" $(8,45 \%)$. Isso equivale a dois terços dos cidadãos que identificaram o nível de instrução formal que possuem e confirma a hipótese de que o uso do direito de acesso à informação é mais frequente entre os cidadãos com nível de escolaridade mais alto. É de se observar que as análises indicam o predomínio do sexo masculino entre os requerentes que declararam possuir nível superior de ensino, enquanto aqueles que declararam ter cursado uma pós-graduação concentram-se predominantemente no sexo feminino;

- as ocupações principais que mais concentram solicitantes de acesso à informação são "outras" (profíssões diferentes das oferecidas no cadastro), com 22\% do total, seguida por "empregados no setor privado", com 18\%, e "estudantes" e "servidores públicos federais", com $12 \%$ e $11 \%$ respectivamente, considerando a participação no total de profissões informadas. Aqui cabe notar que o percentual de cidadãos que registraram a profissão como "outra" pode ser resultado da ambiguidade das opções apresentadas para registro da profissão. Conforme ressaltado anteriormente, a lista de profissões do cadastro do e-SIC não contém itens mutuamente excludentes, o que provavelmente ocasionou a inexatidão das informações 
ANGELI, Alzira. Transparência e acesso à informação: quem é o cidadão que demanda a abertura de informações públicas no Brasil?

registradas no campo "profissão". Diante disso, considera-se impossível avaliar, apenas com base nos dados do e-SIC, quais profissões concentram a maior quantidade de demandantes de acesso à informação no Brasil;

- o sudeste é a região do país que concentra mais pedidos de acesso à informação, praticamente a metade do total $(49,87 \%)$, seguida pela região nordeste $(17,16 \%)$ e não pela região sul (14,08\%), como se admitiu numa das hipóteses de trabalho. Note-se que um quarto do total de pedidos $(25,76 \%)$ vieram apenas das cidades de Brasília, Rio de Janeiro e São Paulo. E que Brasília possui quatro vezes mais solicitantes de acesso à informação do que a média dos demais municípios brasileiros.

A partir dos dados dos 164.328 solicitantes de acesso à informação que se identificaram completamente no cadastro no e-SIC, encontrou-se o perfil do cidadão brasileiro "médio" que demandou acesso a informações públicas do governo federal sob a vigência da Lei de Acesso à Informação (até 31 de agosto de 2016): homem, 42 anos de idade, nível superior completo, profissão diferente das oferecidas no cadastro, residente na região sudeste.

O conjunto de dados analisados demonstrou, em linhas gerais, que as variáveis que mais influenciaram o uso do direito de acesso à informação no Brasil, no período examinado, foram a "profissão" e a "idade" dos solicitantes quando tomadas em relação ao local de residência: $18,40 \%$ para a ocupação profissional e 12,19\% para a faixa etária.

Por fim, espera-se que os dados aqui apresentados suscitem algumas reflexões acerca do papel do governo aberto nas democracias contemporâneas, considerando a interação dos diversos atores sociais envolvidos. Com algum conhecimento acerca de quem é o cidadão que está disposto a fazer uso do direito de acesso às informações públicas, os formuladores das políticas de transparência podem melhor direcionar seus esforços para continuar incentivando o cidadão motivado e, sobretudo, buscar atingir os cidadãos apáticos.

\section{REFERÊNCIAS}

BENTHAM, J. Da publicidade. Revista Brasileira de Ciência Política, n. 6, 2011, p. 277-294.

BERTOT, J. C.; McDERMOTT, P.; SMITH, T. Measurement of Open Government: Metrics and Process. System Science (HICSS), 45th Hawaii International Conference on IEEE, 2012.

BRASIL. Lei $\mathrm{n}^{\circ} 12.527$, de 18 de novembro de 2011. Regula o acesso a informações previsto no inciso XXXIII do art. $5^{\circ}$, no inciso II do $\S 3^{\circ}$ do art. 37 e no $\S 2^{\circ}$ do art. 216 da
Constituição
Federal.
Brasília,
2011.
Disponível
em: 
<http://www.planalto.gov.br/ccivil_03/_ato2011-2014/2011/lei/112527.htm>. Acesso em: 20 dez. 2015.

BRASIL. Controladoria Geral da União. Acesso à Informação Pública: Controladoria-Geral da União: Uma introdução à Lei $n^{o}$ 12.527, de 18 de novembro de 2011. Brasília, 2011. Disponível em: <http://www.acessoainformacao.gov.br/central-deconteudo/publicacoes/arquivos/cartilhaacessoainformacao-1.pdf >. Acesso em: 20 dez. 2015.

BRASIL. Instituto Brasileiro de Geografia e Estatística. Pesquisa população por município. Disponível em: <http://cidades.ibge.gov.br>. Acesso em: 30 ago. 2016.

CERVI, E. U. Análise de Dados Categóricos em Ciência Política. E-book Programa de Pósgraduação em Comunicação e Pós-graduação em Ciência Política: Curitiba, 2014.

DAWES, S. S.; HELBIG, N. Information Strategies for Open Government: Challenges and Prospects for Deriving Public Value from Government Transparency. In: WIMMER, M. A. et al. (Ed.). Electronic Government: Lecture Notes in Computer Science. Springer Berlin Heidelberg, 2010, 2 p. 50-60. Disponível em: http://www.ctg.albany.edu/publications/journals/ifip_2010_opengov/ifip_2010_opengov.pdf. Acesso em: 16 jul. 2014.

GUTMANN, A; THOMPSON, D. Democracy and Disagreement. Cambridge: Harvard University Press, 1996. Why Deliberative Democracy? Princeton, NJ: Princeton University Press, 2004.

HABERMAS, J. Mudança estrutural da esfera pública: investigações quanto a uma categoria da sociedade burguesa. Rio de Janeiro: Tempo Brasileiro, 2003.

JANSSEN M.; CHARALABIDIS, Y.; ZUIDERWIJK, A. Benefits, Adoption Barriers and Myths of Open Data and Open Government. Information Systems Management (ISM), v. 29, n. 4, 2012, p. 258-268.

Disponível em: <http://www.tandfonline.com/doi/full/10.1080/10580530.2012.716740>. Acesso em: 16 jul. 2014.

MARQUES, F., MIOLA, E. "Deliberação mediada: Uma tipologia das funções dos media para a formação do debate público". Estudos em Comunicação, n. 7, v. 1, 2010, p. 1-28.

MARQUES, F. P. J. A. Participação Política e Internet: meios e oportunidades digitais de participação civil na democracia contemporânea, com um estudo de caso do estado brasileiro. 2008. 498 p. Tese (Doutorado em Comunicação e Cultura Contemporâneas). Universidade Federal da Bahia, Salvador. Disponível em: <http://www.repositorio.ufc.br:8080/ri/bitstream/123456789/671/1/2008_tese_\%20fpjamarqu es.pdf >. Acesso em: 20 dez. 2015.

. Internet e Transparência Política. In: XXIII Encontro Anual da Associação Nacional dos Programas de Pós-Graduação em Comunicação - Compós, 2014, Belém. Disponível<http://compos.org.br/encontro2014/anais/Docs/GT05_COMUNICACAO_E_POL ITICA/artigoformatadocompos2014-gtcomunicacaoepolitica_2173.pdf >.Acesso 20 dez. 2015. 
ANGELI, Alzira. Transparência e acesso à informação: quem é o cidadão que demanda a abertura de informações públicas no Brasil?

MENDEL, T. Freedom of Information: A Comparative Legal Survey. Second Edition. UNESCO: Paris, 2008.

NORRIS, P. Digital Divide: Civic Engagement, Information Poverty, and the Internet Worldwide. Cambridge: Cambridge University Press, 2001, edição Kindle, cap. 12, 2642.

SAMPAIO, R. C. Participação política e os potenciais democráticos da internet. Revista Debates, v. 4, n. 1, 2010, p. 29-53.

. Do Conceito de Governo Aberto às suas Relações com a E-Democracia. In: PIMENTA, M. S.; CANABARRO, D. R. (Org.). Governança Digital. Porto Alegre: UFRGS/CEGOV, 2014, p. 12-22.

STRATHERN, M. The Tyranny of Transparency. British Educational Research Journal, Cardiff University Press, Wales-UK, v. 26, n. 3, p. 309-321, jun. 2000. Disponível em: <http://onlinelibrary.wiley.com/doi/10.1080/713651562/pdf>. Acesso em: 21 nov. 2014. 